\title{
Free vibration analysis of moderately thick functionally graded skew plates
}

\author{
Jyoti Vimal $^{\mathrm{a}^{*}}$, R K Srivastava ${ }^{\mathrm{a}^{*}}$, A D Bhatt ${ }^{\mathrm{a}}$ and Avadesh K Sharma ${ }^{\mathrm{b}}$
}

${ }^{a}$ Department of Mechanical Engineering, Motilal Nehru National Institute of Technology, Allahabad, India ${ }^{b}$ Department of Mechanical Engineering, Madhav Institute of Technology \& Science Gwalior, India

\begin{tabular}{|c|c|}
\hline $\begin{array}{l}\text { ART ICLE I NFO } \\
\end{array}$ & A B S T RACT \\
\hline $\begin{array}{l}\text { Article history: } \\
\text { Received January 29, } 2014 \\
\text { Received in Revised form } \\
\text { April, } 14,2014 \\
\text { Accepted } 8 \text { April } 2014 \\
\text { Available online } \\
10 \text { April } 2014 \\
\text { Keywords: } \\
\text { Functionally graded materials } \\
\text { Free vibration }\end{array}$ & $\begin{array}{l}\text { Finite element method is used to study the free vibration analysis of functionally graded skew } \\
\text { plates. The material properties of the skew plates are assumed to vary continuously through } \\
\text { their thickness according to a power-law distribution of the volume fractions of the plate } \\
\text { constituents. The first order shear deformation theory is used to incorporate the effects of } \\
\text { transverse shear deformation and rotary inertia. Convergence study with respect to the number } \\
\text { of nodes has been carried out and the results are compared with those from past investigations } \\
\text { available in the literature. Two types of functionally graded skew plates - Al/ZrO2 and } \\
\mathrm{Al} / \mathrm{Al} 2 \mathrm{O} 3 \text { are considered in this study and the effects of the volume fraction, different external } \\
\text { boundary conditions and thickness ratio on the natural frequencies are studied in detail. }\end{array}$ \\
\hline
\end{tabular}

\section{Introduction}

Functionally graded materials are a class of composites that have continuous variation of material properties from one surface to another and thus eliminate the stress concentration found in laminated composites. A typical functionally graded material is made from a mixture of ceramic and metal. These materials are often isotropic but nonhomogeneous. The gradation of properties in an FGM reduces the thermal stresses, residual stresses, and stress concentrations found in traditional composites. The reason for interest in functionally graded materials (FGMs) is that it may be possible to create certain types of FGM structures capable of adapting to operating conditions. The increase in FGM applications requires accurate models to predict their responses.

There are many approaches used to describe the material gradient of FGMs which are manufactured from two phases of materials. In general, most of the approaches are based on the volume fraction distribution rather than developed from actual graded microstructures (Bao and

* Corresponding author. Tel: +91-9479934701 E-mail addresses: jyoti_vimal@yahoo.com (J. Vimal) 
Wang 1995, Frostig and Shenhar 1995). Reddy (2000) presented a theoretical formulation and finite element models for functionally graded plates (FGPs) based on the third-order shear deformation theory. The formulations accounted for the thermo mechanical coupling, time dependency, and von Ka'rma' n-type geometric nonlinearity of the plates. A review on the stress and vibration analysis of composite plates is studied by Sharma and Mittal (2010). Free vibration analysis of laminated composite plates with elastically restrained edges using FEM is studied by Sharma and Mittal (2013). The governing equations employed are based on the first order shear deformation theory including the effects of rotary inertia. Several combinations of translational and rotational elastic edge constraints are considered.

Fukui and Yamanaka (1992) examined the effects of the gradation of components on the strength and deformation of thick-walled functionally gradient material tubes under internal pressure. Fukui et al. (1993) further extended their previous work by considering a thick-walled FGM tube under uniform thermal loading, and investigated the effect of graded components on residual stresses. They generated an optimum composition of the FGM tube by minimizing the compressive circumferential stress at the inner surface. Neves et al. (2013) developed a higher order shear deformation theory (HSDT) with cubic and parabolic variations for in-plane and transverse displacements, respectively, based on Carrera's unified formulation. With the use of polynomial functions in aforementioned works, trigonometric functions are also employed in the development of HSDTs. The frequency characteristics of thick annular FGPs of variable thickness were analyzed by Efraim and Eisenberger (2007), who utilized the first-order shear deformation theory and exact element method to derive the stiffness matrix.

Recently, Matsunaga (2008) carried out an analysis of the free vibration and stability of FGPs using the two-dimensional higher-order deformation theory. Xiang et al. (2011) and Xiang and Kang (2013) proposed a n-order shear deformation theory in which Reddy's theory can be considered as a specific case. The methods employed in the paper included a higher order shear deformation theory and two novel solutions for FGM structures. According to this paper, the application of the normal deformation theory may be justified if the in-plane size to thickness is equal to or smaller than 5 . Researchers have also turned their attention to the vibration and dynamic response of FGM's structures (Yang and Shen 2003, Huang and Shen 2004). Wu et al (2007) presented exact solutions for free vibration analysis of rectangular plates using Bessel functions with three edges conditions. Matsunaga (2008) presented in his paper, the analysis of natural frequencies and buckling of FGM's plates by taking into account the effects of transverse shear and normal deformations and rotary inertia. For plates with cutouts, Chai (1996) presented finite element and some experimental results on the free vibration of symmetric composite plates with central hole. Thus, needs exist for the development of shear deformation theory which is simple to use. From the review of the above literature it is observed that very little work has been done yet on the natural frequencies of the functionally graded skew plates.

The aim of this paper is to develop a simple first order shear deformation theory for the free vibration analysis of functionally graded skew plates. The first order shear deformation theory is used to incorporate the effects of transverse shear deformation and rotary inertia. Numerical examples are presented to verify the accuracy of the present theory. This work, thus, aims to study the free vibration problem of functionally graded skew plates which have not been studied in detail as yet. An FGM's gradation in material properties allows the designer to tailor material response to meet design criteria. The developed formulation is validated by extensive convergence and comparison studies of functionally graded - $\mathrm{Al} / \mathrm{ZrO}_{2}$ and $\mathrm{Al} / \mathrm{Al}_{2} \mathrm{O}_{3}$ skew plates. The variation of natural frequencies is studied with respect to the volume fraction exponent, different external boundary conditions and thickness ratio. These results are presented through graphical plots.

\section{Functionally Graded Material Properties}


A functionally graded material plate as shown in Fig. 1 and Fig. 2 is considered to be a plate of uniform thickness that is made of ceramic and metal. The material property is to be graded through the thickness according to a Power-Law distribution. On the basic of the rule of mixture, the effective material properties, $P$, can be written as

$P=P_{m} V_{m}+P_{c} V_{c}$

where $P_{m}, P_{c}, V_{m}$ and $V_{c}$ are the material properties and the volume fraction of the metal and ceramic, respectively, the compositions represent in relation to

$V_{c}+V_{m}=1$.

The power law distribution based on the rule of mixture was introduced by Wakashima et al. (1990) in order to define the effective material properties of FGMs. The volume fraction of ceramic ( $V_{c}$ ) can then be written as follows:

$V_{c}=\left(\frac{z}{h}+\frac{1}{2}\right)^{n} \quad(n \geq 0)$,

where the positive number $n \quad(0 \leq n \leq \infty)$ is the power law or the volume fraction index. $z$ is a distance parameter along the graded direction, while, $h$ is the total length of the direction. To find out the results of material properties according to the power law distribution, this can be achieved by substituting the equations of material volume fractions Eq. (2) and Eq. (3) into Eq. (1).

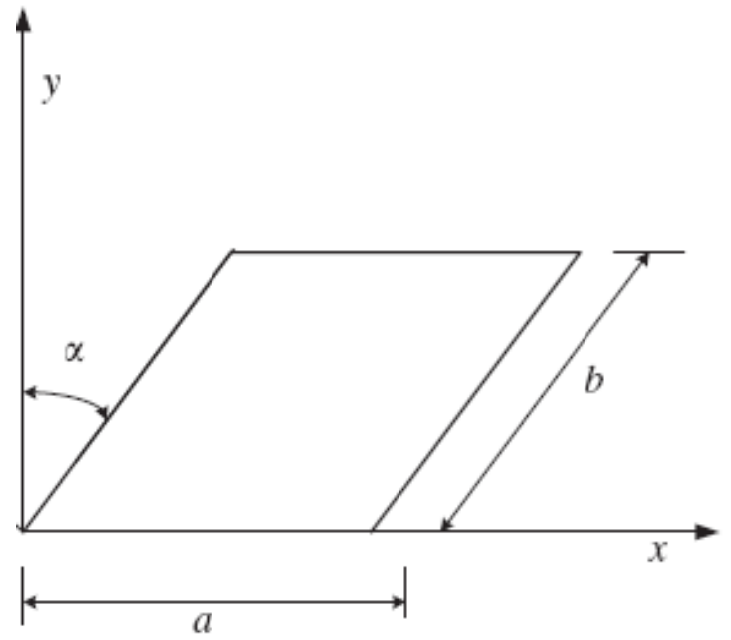

Fig. 1. Geometry of a skew plate

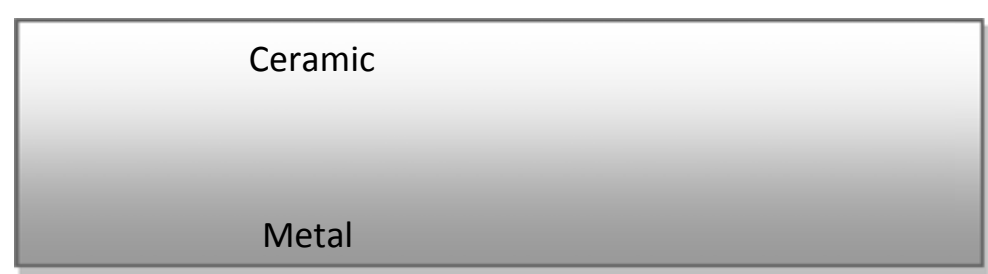

Fig. 2. Functionally Graded Plate

\subsection{Functionally Graded Plate Elements}

SOLID187 element is a higher order 3-D, 10-node element. SOLID187 has a quadratic displacement behavior and is well suited to modeling irregular meshes (such as those produced from various CAD/CAM systems). The element is defined by 10 nodes having three degrees of freedom at each node: translations in the nodal $\mathrm{x}, \mathrm{y}$, and $\mathrm{z}$ directions. The element has plasticity, hyperelasticity, creep, stress stiffening, large deflection, and large strain capabilities. It also has mixed formulation capability for simulating deformations of nearly incompressible elastic-plastic materials, and fully incompressible hyperelastic materials. 

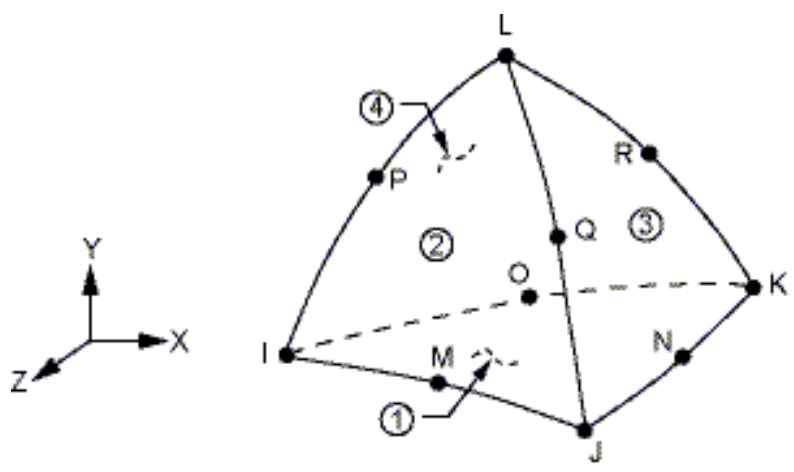

Fig. 3. SOLID 187 element

The geometry, node locations, and the coordinate system for this element are shown in Fig. 3. In addition to the nodes, the element input data includes the orthotropic or anisotropic material properties.

\section{Mathematical Formulation}

Fig. 1 shows the geometry of a Functionally Graded Plates plate. Considering the first order shear deformation theory, the displacement fields are expressed as follows (Reddy, 1997).

$$
\left.\begin{array}{c}
u(x, y, z, t)=u_{0}(x, y, t)+z \phi_{x}(x, y, t) \\
v(x, y, z, t)=v_{0}(x, y, t)+z \phi_{y}(x, y, t) \\
w(x, y, z, t)=w_{0}(x, y, t)
\end{array}\right\}
$$

where $\left(u_{0}, v_{0}, w_{0}, \phi_{x}, \phi_{y}\right)$ are unknown functions to be determined. As before, $\left(u_{0}, v_{0}, w_{0}\right)$ denote the displacements of a point on the plane $z=0$; Note that

$\frac{\partial u}{\partial z}=\phi_{x}, \quad \frac{\partial v}{\partial z}=\phi_{y}$,

which indicate that $\phi_{x}$ and $\phi_{y}$ are the rotations of a transverse normal about the $y$ and $x$ axes, respectively. The strain displacement relations can be expressed as follows.

In-plane strains at the mid-plane are:

$\epsilon_{x}^{0}=\frac{\partial u_{0}}{\partial x}$

$\epsilon_{y}^{0}=\frac{\partial v_{0}}{\partial y}$

$\epsilon_{x y}^{0}=\frac{\partial u_{0}}{\partial y}+\frac{\partial v_{0}}{\partial x}$

$k_{x}^{0}=\frac{\partial \phi_{x}}{\partial x}$

$k_{y}^{0}=\frac{\partial \phi_{y}}{\partial y}$

$k_{x y}^{0}=\frac{\partial \phi_{x}}{\partial y}+\frac{\partial \phi_{y}}{\partial x}$

The shear strains in $x z$ and $y z$ planes are:

$\varepsilon_{x z}=\phi_{x}+\frac{\partial w_{0}}{\partial x}$ 
$\varepsilon_{y z}=\phi_{y}+\frac{\partial w_{0}}{\partial y}$

The strain components at any point can thus be expressed as:

$$
\begin{aligned}
& \left\{\begin{array}{l}
\varepsilon_{x x} \\
\varepsilon_{y y} \\
\varepsilon_{y z} \\
\varepsilon_{x z} \\
\varepsilon_{x y}
\end{array}\right\}=\left\{\begin{array}{l}
\varepsilon_{x x}{ }^{(0)} \\
\varepsilon_{y y}{ }^{(0)} \\
\varepsilon_{y z}{ }^{(0)} \\
\varepsilon_{x z}{ }^{(0)} \\
\varepsilon_{x y}{ }^{(0)}
\end{array}\right\}+z\left\{\begin{array}{l}
k_{x x}^{(0)} \\
k_{y y}^{(0)} \\
0 \\
0 \\
k_{x y}^{(0)}
\end{array}\right\} \\
& \left\{\begin{array}{l}
\varepsilon_{x x} \\
\varepsilon_{y y} \\
\varepsilon_{y z} \\
\varepsilon_{x z} \\
\varepsilon_{x y}
\end{array}\right\}=\left\{\begin{array}{c}
\frac{\partial u_{0}}{\partial x} \\
\frac{\partial v_{0}}{\partial y} \\
\phi_{y}+\frac{\partial w_{0}}{\partial y} \\
\phi_{x}+\frac{\partial w_{0}}{\partial x} \\
\frac{\partial u_{0}}{\partial y}+\frac{\partial v_{0}}{\partial x}
\end{array}\right\}+z\left\{\begin{array}{c}
\frac{\partial \phi_{x}}{\partial x} \\
\frac{\partial \phi_{y}}{\partial y} \\
0 \\
0 \\
\frac{\partial \phi_{x}}{\partial y}+\frac{\partial \phi_{y}}{\partial x}
\end{array}\right\}
\end{aligned}
$$

\section{Numerical Results and Discussion}

The present study gives the free vibration results of moderately thick functionally graded skew plates. The effects of volume fraction index, boundary conditions and length to thickness ratio are studied. To verify the results, the convergence study of functionally graded skew plates is first examined with respect to the mesh dimensions $(\mathrm{M} \times \mathrm{N})$. Plates with the length-to-thickness ratios $(a / h$ $=10$ ) and the values of the volume fraction exponent, $n=0,0.5,1,3,5,10,200$ are considered. The default parameter values of the functionally graded plates are as given in Table 1 .

Table 1. Properties of the FGM components:

\begin{tabular}{llll}
\hline \multirow{2}{*}{ Material } & \multicolumn{3}{c}{ Properties } \\
\cline { 2 - 4 } & $E\left(\mathrm{~N} / \mathrm{m}^{2}\right)$ & $v$ & $\rho\left(\mathrm{Kg} / \mathrm{m}^{3}\right)$ \\
\hline Aluminum $(\mathrm{Al})$ & $70.0 \times 10^{9}$ & 0.30 & 2707 \\
Alumina $\left(\mathrm{Al}_{2} \mathrm{O}_{3}\right)$ & $380 \times 10^{9}$ & 0.30 & 3800 \\
Zirconia $\left(\mathrm{ZrO}_{2}\right)$ & $151 \times 10^{9}$ & 0.30 & 3000 \\
\hline
\end{tabular}

The accuracy and convergence behaviors of the first eight frequency parameters are tested in Tables 2 and 3 for the functionally graded skew plates with clamped edges. In order to show the accuracy of methodology used for free vibration analysis of FG skew plates, the fundamental natural frequencies of different plates are compared with the solutions presented by Zhao et al. (2009). To validate the isotropic skew plate with respect to the volume fraction index, $n=0$ and skew angle, $\alpha=30$, the convergence study is as given in Table 2 , and to validate the isotropic skew plate with respect to the volume fraction index $n=0$ and $\alpha=15$, the convergence study is as given in Table 3 . It can be seen in these Tables that convergence is achieved at the mesh size of (20 x 20). It is obvious that by increasing the number of grid points, the accuracy of the results is also increases. It is found that the results of this study show a trend of monotonic convergence trend, and the solutions are 
slightly larger than those given in the literature. The difference ranges from $1 \%$ to $4 \%$ for the plates with $a / h=10$. These discrepancies may be due to the different types of plate theories and the solution strategies adopted.

Table 2. Convergence study with respect to the results given by Zhao et al. (2009) for a isotropic skew plate with the volume fraction index $n=0$, skew angle $\alpha=30$ and $a / h=10$ (fully clamped for external boundaries)

\begin{tabular}{|c|c|c|c|c|c|c|c|c|}
\hline \multirow[t]{2}{*}{$M=N$} & \multicolumn{8}{|c|}{$\bar{\omega}=\omega a^{2} / h \sqrt{\rho_{c} / E_{c}}$} \\
\hline & $\omega=1$ & 2 & 3 & 4 & 5 & 6 & 7 & 8 \\
\hline 4 & 13.8579 & 24.0821 & 30.4328 & 34.4091 & 38.8752 & 45.6571 & 46.1185 & 47.856 \\
\hline 6 & 13.0626 & 22.0612 & 27.7627 & 31.0500 & 38.7255 & 41.3194 & 41.4549 & 45.3463 \\
\hline 8 & 12.8571 & 21.5661 & 27.0754 & 30.1671 & 38.6724 & 39.9043 & 39.9583 & 44.4235 \\
\hline 10 & 12.7633 & 21.3855 & 26.7761 & 29.8456 & 38.6494 & 39.3915 & 39.4154 & 43.6804 \\
\hline 12 & 12.7243 & 21.2898 & 26.6592 & 29.6906 & 38.6387 & 39.1232 & 39.1435 & 43.4103 \\
\hline 14 & 12.6960 & 21.2305 & 26.5972 & 29.6021 & 38.6316 & 38.9832 & 39.0142 & 43.2864 \\
\hline 16 & 12.6561 & 21.1676 & 26.5202 & 29.4985 & 38.6237 & 38.8229 & 38.8398 & 43.1340 \\
\hline 18 & 12.4896 & 20.7912 & 26.0118 & 28.8945 & 37.9311 & 37.9621 & 38.6157 & 42.0890 \\
\hline 20 & 12.4790 & 20.7744 & 25.9835 & 28.8697 & 37.8895 & 37.9232 & 38.6122 & 42.0341 \\
\hline Zhao et al. (2009) & 12.2116 & 20.349 & 25.452 & 28.226 & & & & \\
\hline
\end{tabular}

Table 3. Convergence of non-dimensional fundamental frequencies of isotropic skew plate with the volume fraction index $n=0$ and $\alpha=15$, for $(n=0, a / h=10)$ (fully clamped for external boundaries)

\begin{tabular}{cllllllll}
\hline & \multicolumn{8}{c}{$\bar{\omega}=\omega a^{2} / h \sqrt{\rho_{c} / E_{c}}$} \\
$\mathrm{M}=\mathrm{N}$ & $\mathrm{i}=1$ & 2 & 3 & 4 & 5 & 6 & 7 & 8 \\
\hline 4 & 11.9264 & 22.0603 & 25.531 & 32.2828 & 37.305 & 40.433 & 43.452 & 45.604 \\
8 & 10.822 & 19.647 & 21.9753 & 28.2684 & 34.7757 & 36.252 & 37.019 & 38.8327 \\
10 & 10.7494 & 19.4664 & 21.768 & 27.9389 & 34.2798 & 35.7331 & 36.9924 & 38.2898 \\
12 & 10.7051 & 19.3433 & 21.6511 & 27.7423 & 34.0124 & 35.4869 & 36.9729 & 37.9276 \\
14 & 10.6892 & 19.2955 & 21.6131 & 27.6396 & 33.9043 & 35.3664 & 36.9632 & 37.7425 \\
16 & 10.6378 & 19.2034 & 21.4678 & 27.474 & 33.6882 & 35.0512 & 36.9534 & 37.3998 \\
18 & 10.5271 & 18.9138 & 21.1614 & 27.0205 & 33.0187 & 34.4481 & 36.7719 & 36.9446 \\
\hline 20 & 10.528 & 18.92 & 21.1712 & 27.0232 & 33.0355 & 34.4507 & 36.7799 & 36.9419 \\
\hline
\end{tabular}

The comparison of the results for the non dimensional fundamental frequency for clamped $\mathrm{Al} / \mathrm{ZrO}_{2}$ FG skew plates with length-to-thickness ratio, $a / h=10$ and skew angle, $\alpha=30$ and the volume fraction exponent ( $n=0$ and $n=3.0$ ) are shown in Table 4. To compare the solutions the results of Zhao et al. (2009) is cited.

Table 4. Comparison of the non dimensional fundamental frequency $\bar{\omega}$ for clamped skew $\mathrm{Al} / \mathrm{ZrO}_{2}$ FG plates $(a / b=1, a / h=10, \alpha=30)$

\begin{tabular}{|c|c|c|c|c|}
\hline \multirow[b]{2}{*}{ Mode } & \multicolumn{2}{|l|}{$n=0$} & \multicolumn{2}{|l|}{$n=3.0$} \\
\hline & Present & Zhao et al. (2009) & Present & Zhao et al. (2009) \\
\hline 1 & 12.4790 & 12.2116 & 9.2953 & 9.9388 \\
\hline 2 & 20.7744 & 20.349 & 15.4732 & 16.5315 \\
\hline 3 & 25.9835 & 25.452 & 19.3539 & 20.659 \\
\hline 4 & 28.8697 & 28.226 & 21.5033 & 22.902 \\
\hline 5 & 37.8895 & & 28.2214 & \\
\hline 6 & 37.9232 & & 28.2462 & \\
\hline 7 & 38.6122 & & 28.7599 & \\
\hline 8 & 42.0341 & & 31.3086 & \\
\hline
\end{tabular}

Table 5 shows the variation of the non-dimensional frequency parameter with the volume fraction exponent for the $\mathrm{Al} / \mathrm{ZrO}_{2} \mathrm{FG}$ skew plates $(a / b=1, a / h=10, \alpha=15)$. Only the results for the first eight modes are computed. For the plates with the CFCF, CFFF and CCCC boundary conditions (where $\mathrm{C}$ and $\mathrm{F}$ denote Clamped and Free, respectively), the frequencies in all eight modes decreaseas 
as the volume fraction exponent $n$ increases. This is clear that a larger volume fraction exponent means that a plate has a smaller ceramic component and that its stiffness is thus reduced.

Table 5. Non-dimensionalized frequencies of the skew plate for a fully clamped $\mathrm{Al} / \mathrm{ZrO}_{2}$ plate $(a / b=1, a / h=10, \alpha=15)$

\begin{tabular}{cllccccccc}
\hline $\begin{array}{c}\text { Boundary } \\
\text { condition }\end{array}$ & $n$ & & \multicolumn{7}{c}{$\bar{\omega}=\omega a^{2} / h \sqrt{\rho_{c} / E_{c}}$} \\
& & $\bar{\omega}=1$ & 2 & 3 & 4 & 5 & 6 & 7 & 8 \\
\hline \multirow{4}{*}{ CFCF } & 0 & 6.6073 & 7.5543 & 12.0619 & 16.8716 & 18.1070 & 18.2859 & 20.5937 & 23.7252 \\
& 0.5 & 5.9463 & 6.7985 & 10.8557 & 15.1836 & 16.2950 & 16.4571 & 18.5330 & 21.3509 \\
& 1 & 5.5459 & 6.3407 & 10.1242 & 14.1607 & 15.1978 & 15.3492 & 17.2851 & 19.9127 \\
& 5 & 4.7843 & 5.4692 & 8.7355 & 12.2239 & 13.1157 & 13.2256 & 14.9197 & 17.1939 \\
& 10 & 1.4998 & 1.7144 & 2.7384 & 3.8320 & 4.1116 & 4.1458 & 4.6769 & 5.3899 \\
\hline & 0 & 1.0745 & 2.5000 & 6.3454 & 6.6325 & 7.4851 & 9.3634 & 14.0412 & 15.4936 \\
CFFF & 0.5 & 0.9671 & 2.2499 & 5.7105 & 5.9694 & 6.7364 & 8.4266 & 12.6366 & 13.9438 \\
& 1 & 0.9020 & 2.0983 & 5.3260 & 5.5674 & 6.2828 & 7.8592 & 11.7856 & 13.0050 \\
& 5 & 0.7774 & 1.8091 & 4.5920 & 4.7969 & 5.4170 & 6.7779 & 10.167 & 11.2055 \\
& 10 & 0.2437 & 0.5671 & 1.4395 & 1.5037 & 1.6981 & 2.1247 & 3.1872 & 3.5126 \\
\hline & 0 & 10.5085 & 18.8695 & 21.1145 & 26.9417 & 32.9195 & 34.3383 & 36.6426 & 36.9366 \\
CCCC & 0.5 & 9.4573 & 16.9823 & 18.9988 & 24.2460 & 29.6251 & 30.8968 & 32.9753 & 33.2419 \\
& 1 & 8.8201 & 15.8390 & 17.7200 & 22.6129 & 27.6298 & 28.8165 & 30.7551 & 31.0031 \\
& 5 & 7.6133 & 13.679 & 15.3067 & 19.5372 & 23.8873 & 24.9119 & 26.5910 & 26.7177 \\
& 10 & 7.5474 & 13.5612 & 15.1739 & 19.3681 & 23.680 & 24.6958 & 26.3608 & 26.4856 \\
\hline
\end{tabular}

Table 6 and Table 7 show the frequencies of the first eight modes for clamped functionally graded $\mathrm{Al} / \mathrm{ZrO} 2$ and $\mathrm{Al} / \mathrm{Al}_{2} \mathrm{O}_{3}$ skew plates $(a / h=10, a / b=1)$. The volume fraction exponent $n$ varies between 0 and 3 , and the skew angle ranges from $15^{\circ}$ to $60^{\circ}$. It is observed that, for plates with a fixed volume fraction exponent, the non-dimensional frequencies in all eight modes increase with increasing the skew angle, whereas for plates with a fixed skew angle, the non-dimensional frequencies gradually decreases as the volume fraction exponent increases.

Table 6. Non-dimensionalized frequencies with the skew angle $\alpha$ for a fully clamped Al/ZrO2 plate $(a / b=1, a / h=10)$

\begin{tabular}{|c|c|c|c|c|c|c|c|c|c|}
\hline \multirow[b]{2}{*}{$N$} & \multirow[b]{2}{*}{$\alpha$} & \multicolumn{8}{|c|}{$\overline{\bar{\omega}}=\left(\omega a^{2} / h\right) \sqrt{\rho_{c} / E_{c}}$} \\
\hline & & $i=1$ & 2 & 3 & 4 & 5 & 6 & 7 & 8 \\
\hline \multirow{5}{*}{0} & 15 & 10.5085 & 18.8695 & 21.1145 & 26.9417 & 32.9195 & 34.3383 & 36.6426 & 36.9366 \\
\hline & 30 & 12.4790 & 20.7744 & 25.9835 & 28.8697 & 37.8895 & 37.9232 & 38.6122 & 42.0341 \\
\hline & 45 & 17.0815 & 25.9366 & 34.3524 & 36.1750 & 43.3563 & 43.5166 & 48.8586 & 52.3168 \\
\hline & 60 & 28.5190 & 38.6945 & 47.9597 & 55.4766 & 57.4560 & 59.2493 & 66.9009 & 73.7599 \\
\hline & 15 & 9.4741 & 17.0230 & 19.0475 & 24.3124 & 29.7252 & 31.0004 & 33.0896 & 33.2472 \\
\hline \multirow{3}{*}{0.5} & 30 & 11.2312 & 18.6959 & 23.3843 & 25.9817 & 34.1000 & 34.1301 & 34.7501 & 37.8302 \\
\hline & 45 & 15.3652 & 23.3285 & 30.9004 & 32.5033 & 38.9939 & 39.1648 & 43.9337 & 47.0608 \\
\hline & 60 & 25.6665 & 34.8253 & 43.1615 & 49.9275 & 51.7075 & 53.3237 & 60.2084 & 66.3925 \\
\hline \multirow{4}{*}{1} & 15 & 8.8361 & 15.8770 & 17.7651 & 22.6749 & 27.7228 & 28.9131 & 30.8614 & 31.0084 \\
\hline & 30 & 10.4749 & 17.4375 & 21.8097 & 24.2327 & 31.8037 & 31.8311 & 32.4094 & 35.2823 \\
\hline & 45 & 14.3308 & 21.7574 & 28.8192 & 30.3141 & 36.3680 & 36.5275 & 40.9749 & 43.8912 \\
\hline & 60 & 23.9378 & 32.4803 & 40.2549 & 46.5648 & 48.2253 & 49.7326 & 56.1541 & 61.9212 \\
\hline \multirow{4}{*}{3} & 15 & 7.8409 & 14.0890 & 15.7646 & 20.1217 & 24.6011 & 25.6567 & 27.3854 & 27.5156 \\
\hline & 30 & 9.2953 & 15.4732 & 19.3539 & 21.5033 & 28.2214 & 28.2462 & 28.7599 & 31.3086 \\
\hline & 45 & 12.7163 & 19.3079 & 25.5735 & 26.9010 & 32.2721 & 32.4138 & 36.3610 & 38.9487 \\
\hline & 60 & 21.2420 & 28.8227 & 35.7216 & 41.3212 & 42.7940 & 44.1321 & 49.8301 & 54.9479 \\
\hline
\end{tabular}

In addition to the observations made from Tables 6 and 7, it is clear that the variation in the non dimensional frequencies is less when the skew angle varies from $0^{0}$ to $30^{\circ}$, but the variation in the non dimensional frequencies is more when the skew angle rises from $30^{\circ}$ to $60^{\circ}$. The variation in 
frequencies in the FG skew plates with different volume fraction exponents also increase as the skew angle increases.

Table 7. Non-dimensionalized frequencies with the skew angle $\alpha$ for a fully clamped $\mathrm{Al} / \mathrm{Al}_{2} \mathrm{O}_{3}$ plate $(a / b=1, a / h=10)$

\begin{tabular}{|c|c|c|c|c|c|c|c|c|c|}
\hline \multirow[b]{2}{*}{$N$} & \multirow[b]{2}{*}{$\alpha$} & \multicolumn{8}{|c|}{$\bar{\omega}=\left(\omega a^{2} / h\right) \sqrt{\rho_{c} / E_{c}}$} \\
\hline & & $i=1$ & 2 & 3 & 4 & 5 & 6 & 7 & 8 \\
\hline \multirow{4}{*}{0} & 15 & 10.5273 & 18.9153 & 21.1653 & 27.0148 & 33.0290 & 34.4465 & 36.7674 & 36.9427 \\
\hline & 30 & 12.4795 & 20.7744 & 25.9838 & 28.8702 & 37.8902 & 37.9235 & 38.6128 & 42.0352 \\
\hline & 45 & 17.0762 & 25.9398 & 34.3679 & 36.1360 & 43.3660 & 43.5180 & 48.8354 & 52.3200 \\
\hline & 60 & 28.5196 & 38.6970 & 47.9595 & 55.4773 & 57.4552 & 59.2515 & 66.9024 & 73.7699 \\
\hline \multirow{4}{*}{0.5} & 15 & 7.8696 & 14.1395 & 15.8215 & 20.1939 & 24.6901 & 25.7494 & 27.4848 & 27.6155 \\
\hline & 30 & 9.3285 & 15.5293 & 19.4236 & 21.5812 & 28.3242 & 28.3487 & 28.8639 & 31.4224 \\
\hline & 45 & 12.7654 & 19.3903 & 25.6910 & 27.0123 & 32.4170 & 32.5308 & 36.5054 & 39.1104 \\
\hline & 60 & 21.3192 & 28.9268 & 35.8514 & 41.4703 & 42.9494 & 44.2921 & 50.0103 & 55.1468 \\
\hline \multirow{4}{*}{1} & 15 & 6.8555 & 12.3174 & 13.7826 & 17.5921 & 21.5083 & 22.4313 & 23.9430 & 24.0567 \\
\hline & 30 & 8.1266 & 13.5281 & 16.9204 & 18.8003 & 24.6737 & 24.6957 & 25.1443 & 27.3730 \\
\hline & 45 & 11.1198 & 16.8915 & 22.3804 & 23.5315 & 28.2400 & 28.3387 & 31.8013 & 34.0707 \\
\hline & 60 & 18.5716 & 25.1990 & 31.2308 & 36.1266 & 37.4146 & 38.5839 & 43.5658 & 48.0400 \\
\hline \multirow{4}{*}{3} & 15 & 5.6567 & 10.1642 & 11.3730 & 14.5165 & 17.7479 & 18.5094 & 19.7572 & 19.8508 \\
\hline & 30 & 6.7060 & 11.1632 & 13.9623 & 15.5136 & 20.3604 & 20.3780 & 20.7487 & 22.5877 \\
\hline & 45 & 9.1758 & 13.9384 & 18.4679 & 19.4173 & 23.3028 & 23.3844 & 26.2414 & 28.1144 \\
\hline & 60 & 15.3251 & 20.7939 & 25.7714 & 29.8108 & 30.8733 & 31.8384 & 35.9494 & 39.6413 \\
\hline
\end{tabular}

Fig. 4 shows a comparison of the fundamental natural frequency parameters of two $\mathrm{Al} / \mathrm{Al}_{2} \mathrm{O}_{3}$ and $\mathrm{Al} / \mathrm{ZrO}_{2}$ clamped functionally graded skew plates. It can be seen that both the curves shows a similar behavior. It is clear that as the volume fraction exponent increases, the frequency parameter starts decreasing. The curves for the plates made of a combination of $\mathrm{Al} / \mathrm{Al}_{2} \mathrm{O}_{3}$ and $\mathrm{Al} / \mathrm{ZrO}_{2}$ shows that the $\mathrm{Al} / \mathrm{ZrO} 2 \mathrm{FG}$ skew plate has the higher values of frequencies than the $\mathrm{Al} / \mathrm{Al}_{2} \mathrm{O}_{3} \mathrm{FG}$ skew plates. $\mathrm{A}$ prominent drop in frequency occurs when the volume fraction exponent varies between 0 and 2, but beyond the values of the volume fraction exponent 5 , both the curves become flatter.

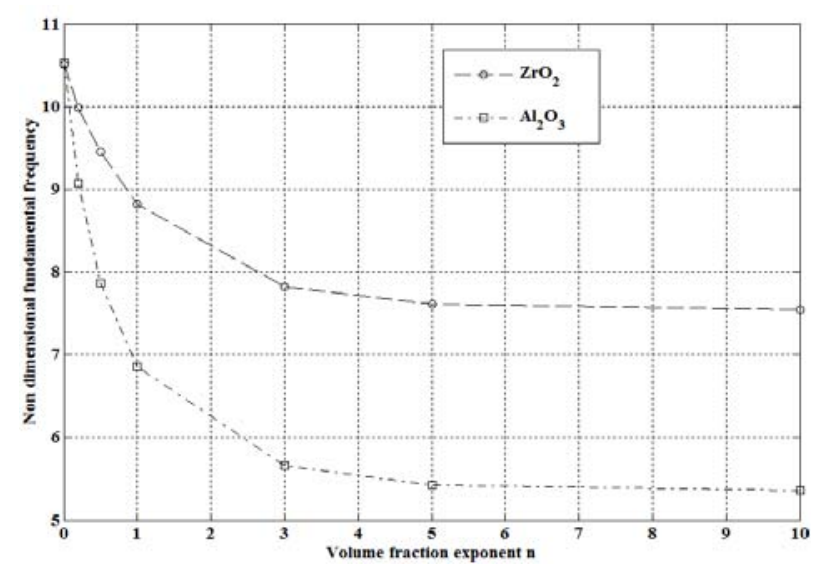

Fig. 4. Variation of the fundamental natural frequency parameter with the volume fraction exponent for fully clamped plates (CCCC)

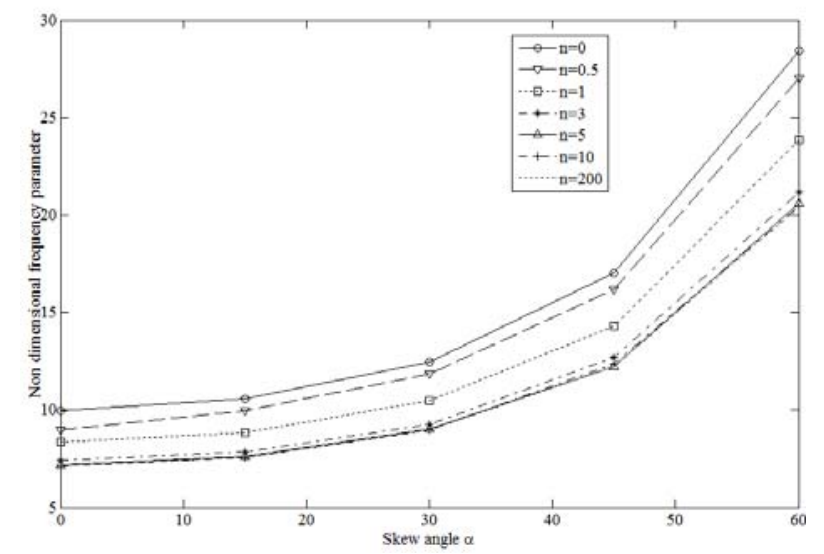

Fig. 5.Variation of the frequency parameter $\bar{\omega}$ with the skew angle for fully clamped $\mathrm{Al} / \mathrm{ZrO} 2$ skew plates

Fig. 5 shows the variation of the non dimensional fundamental frequencies with the skew angle for the clamped plates. In addition to the observations made from Tables 7 and 8 , it is clearly noticed that the frequencies gradually increases as the skew angle varies from $0^{\circ}$ to $30^{\circ}$, but the variations in the frequencies is more when the skew angle varies from $30^{\circ}$ to $60^{\circ}$. The frequency discrepancies 
among the plates with different volume fraction exponents also increase as the skew angle grows. Fig. 6 shows the effects of the volume fraction exponent and length-to-thickness ratio on the fundamental natural frequency parameter of functionally graded clamped skew $\mathrm{Al} / \mathrm{ZrO}_{2}$ plates. It shows that, for plates with a certain volume fraction, the frequency rises as the length-to-thickness ratio increases up to around 25, but when it increases further no variation in the frequency occurs. It is therefore concluded that the effects of the length-to-thickness ratio on the frequency of plates is independent of the variation in the volume fraction.

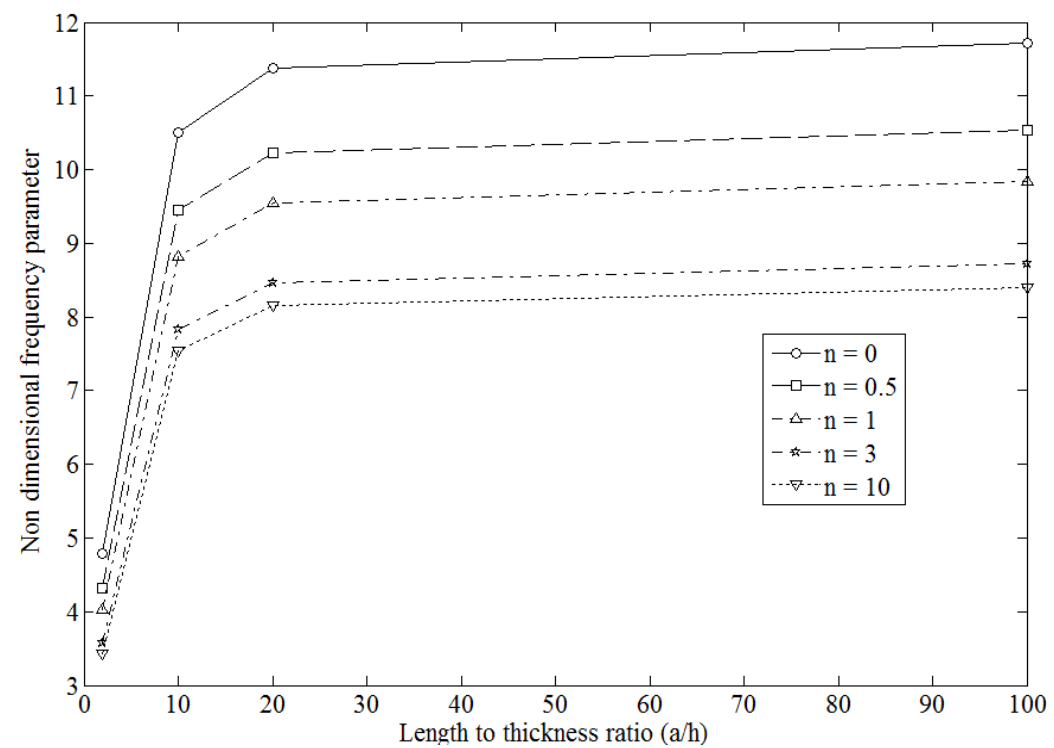

Fig. 6.Variation of the fundamental natural frequency parameter $(\bar{\omega})$ with the length-to-thickness ratio for Clamped skew Al/ZrO2 plates $(\alpha=15)$ FG Plates.

\section{Conclusion}

The free vibration analysis of functionally graded skew plates is carried out using the finite element method. The first-order shear deformation plate theory is used to consider the transverse shear effect and rotary inertia. The properties of functionally graded skew plates are assumed to vary through the thickness according to a power law. The results derived with this method are compared with the solutions available in the literature to validate the accuracy. It is found that when the lengthto-thickness ratio of functionally graded skew plates is increases beyond 25, the variation in the frequency parameter is very negligible and also found that a volume fraction exponent that ranges between 0 and 5 has a significant influence on the frequency.

From this study, it is clear that the effects of the length-to-thickness ratio on the frequency of a FG plate are independent of the volume fraction. For a skew plate, a fast frequency increment trend is observed when the skew angles are greater than $30^{\circ}$.

\section{References}

Bao, G., \& Wang, L. (1995). Multiple cracking in functionally graded ceramic/metal coatings. International Journal of Solids and Structures, 32(19), 2853-2871.

Boay, C. G. (1996). Free vibration of laminated composite plates with a central circular hole. Composite structures, 35(4), 357-368.

Efraim, E., \& Eisenberger, M. (2007). Exact vibration analysis of variable thickness thick annular isotropic and FGM plates. Journal of Sound and Vibration, 299(4), 720-738.

Frostig, Y., \& Shenhar, Y. (1995). High-order bending of sandwich beams with a transversely flexible core and unsymmetrical laminated composite skins. Composites Engineering, 5(4), 405414. 
Fukui, Y., \& Yamanaka, N. (1992). Elastic analysis for thick-walled tubes of functionally graded material subjected to internal pressure. JSME international journal. Ser. 1, Solid mechanics, strength of materials, 35(4), 379-385.

Fukui, Y., Yamanaka, N., \& Wakashima, K. (1993). The stresses and strains in a thick-walled tube for functionally graded material under uniform thermal loading. JSME international journal. Series A, mechanics and material engineering, 36(2), 156-162.

Huang, X. L., \& Shen, H. S. (2004). Nonlinear vibration and dynamic response of functionally graded plates in thermal environments. International Journal of Solids and Structures, 41(9), 2403-2427.

Matsunaga, H. (2008). Free vibration and stability of functionally graded plates according to a 2-D higher-order deformation theory. Composite structures, 82(4), 499-512.

Neves, A. M. A., Ferreira, A. J. M., Carrera, E., Cinefra, M., Roque, C. M. C., Jorge, R. M. N., \& Soares, C. M. M. (2013). Static, free vibration and buckling analysis of isotropic and sandwich functionally graded plates using a quasi-3D higher-order shear deformation theory and a meshless technique. Composites Part B: Engineering, 44(1), 657-674.

Reddy, J. N. (1997). Mechanics of laminated composite plates: theory and analysis (Vol. 1, pp. 95154). Boca Raton: CRC press.

Reddy, J. N. (2000). Analysis of functionally graded plates. International Journal for Numerical Methods in Engineering, 47(1-3), 663-684.

Sharma, A. K., \& Mittal, N. D. (2010). Review on stress and vibration analysis of composite plates. Journal of Applied Sciences(Faisalabad), 10(23), 3156-3166.

Sharma, A. K., \& Mittal, N. D. (2013). Free vibration analysis of laminated composite plates with elastically restrained edges using FEM. Central European Journal of Engineering, 3(2), 306-315.

Wakashima, K., Hirano, T., \& Niino, M. (1990). Space applications of advanced structural materials. ESA SP, 303, 97.

Wu, J. H., Chen, H. L., \& Liu, A. Q. (2007). Exact solutions for free-vibration analysis of rectangular plates using Bessel functions. Journal of Applied Mechanics, 74(6), 1247-1251.

Xiang, S., Jin, Y. X., Bi, Z. Y., Jiang, S. X., \& Yang, M. S. (2011). A n-order shear deformation theory for free vibration of functionally graded and composite sandwich plates. Composite Structures, 93(11), 2826-2832.

Xiang, S., \& Kang, G. W. (2013). A n th-order shear deformation theory for the bending analysis on the functionally graded plates. European Journal of Mechanics-A/Solids, 37, 336-343.

Yang, J., \& Shen, H. S. (2003). Free vibration and parametric resonance of shear deformable functionally graded cylindrical panels. Journal of Sound and Vibration, 261(5), 871-893.

Zhao, X., Lee, Y. Y., \& Liew, K. M. (2009). Free vibration analysis of functionally graded plates using the element-free kp-Ritz method. Journal of Sound and Vibration, 319(3), 918-939. 